\title{
УДК 811.163.1
}

\section{НАЗВАНИЯ ЖИЛИЩ В СТАРОСЛАВЯНСКОМ СЛОВАРЕ (ПО РУКОПИСЯМ X-ХІ ВЕКОВ): СТРУКТУРА СЛОВАРНОЙ СТАТЬИ}

\author{
Е. П. Таргонская (Новосибирск, Россия)
}

\begin{abstract}
В статье анализируются слова, называющие жилище, в «Старославянском словаре (по рукописям X-XI веков)». Цель статьи - выявить специфику построения словарной статьи данного словаря. В работе "Старославянский словарь» квалифицируется, с одной стороны, как двуязычный словарь, а с другой - как исторический. Своеобразие словарной статьи состоит в том, что, помимо традиционных составляющих, в ней дается перевод на два языка - русский и чешский. Кроме того, в конце словарной статьи, после пометы сравни, приводятся, как отмечают авторы словаря, синонимы и дублеты. Рассматривая слова, называющие жилище, автор ставит под сомнение статус этих соответствий. Из "Старославянского словаря» была сделана сплошная выборка слов, называющих жилище, а также их так называемых синонимов и дублетов. Анализ полученного материала позволяет утверждать, что данные слова представляют собой тематическую группу слов-названий жилища, а сам "Старославянский словарь (по рукописям X-ХІ веков)» является не просто словарем для чтения и перевода, но книгой, чтение которой позволяет узнать и понять средневековую христианскую письменность и культуру.
\end{abstract}

Ключевые слова: старославянский язык, словарная статья, синонимы, тематическая группа.

В современной российской лингвистической науке разработана стройная и завершенная типология словарей, в основу которой положены тематика, адресат словаря и объем словника. Лингвистические словари делятся на одно-, дву- и многоязычные. Одноязычные словари, в свою очередь, делятся на системные и справочные. Внутри первых есть толковые (нормативные, исторические и диалектные) и собственно системные словари. Во второй группе выделяются научно- и практически-справочные словари. В каждой группе возможно и более детальное деление. [1-4].
Однако существующая в литературе предмета типология в некоторых случаях позволяет говорить о неком двойственном положении отдельного словаря в этой классификации. Таким словарем, по нашему мнению, является «Старославянский словарь (по рукописям X-XI веков)» [5] (далее - «Старославянский словарь»). Он совмещает признаки, с одной стороны, двуязычного словаря, а с другой - исторического. Цель данной статьи - выявить специфику построения словарной статьи исследуемого словаря.

Таргонская Елена Петровна - кандидат филологических наук, доцент кафедры теории языка и межкультурной коммуникации, Новосибирский государственный педагогический университет.

E-mail: targilena@yandex.ru. 
Словари разных типов имеют разную структуру словарной статьи в зависимости от представленной в ней лексикографической информации [6]. В. А. Козырев и В. Д. Черняк утверждают: «Особое значение для читателей имеют структура словарной статьи, набор ее компонентов, обеспечивающих достоверную информацию о слове, о разных видах его языкового окружения» [1, с. 40]. Рассмотрение того, как строится словарная статья в «Старославянском словаре», предварим описанием основных особенностей самого словаря.

«Старославянский словарь» был впервые издан в 1994 г. под эгидой Института славяноведения и балканистики Российской академии наук и Славянского института академии наук Чешской республики и является коллективным трудом сотрудников этих институтов. Он содержит около 10000 слов. В предисловии отмечается, что он «рассчитан на славистовязыковедов, а также историков, этнографов, юристов, литературоведов, изучающих древнейший период истории, культуры и быта славянских народов. Вместе с тем словарь является учебным пособием для студентов филологиче- ских, исторических и ряда других гуманитарных факультетов, отделений университетов и педагогических институтов» [5, с. 3].

Словарным статьям предшествуют традиционное предисловие и пять справочных статей: «Описание старославянских рукописей», «Фонетико-фонологическая и правописно-графическая характеристика старославянских рукописей», «Нормализация написания заглавного слова основной словарной статьи (фонетическая и морфологическая)», «Построение словарной статьи» и «О произношении старославянских букв».

Автором раздела «Построение словарной статьи» является Р. М. Цейтлин. Она подробно описывает структуру, во многом традиционную для словарей такого типа: дается заглавное слово со своими грамматическими характеристиками, количество его употреблений в рукописях, греческое соответствие (и латинское - для Киевских листков), далее перевод, переносные значения (если есть) и иллюстративные примеры из рукописей.

Приведем пример словарной статьи «Старославянского словаря» (рис. 1).

Рисунок 1

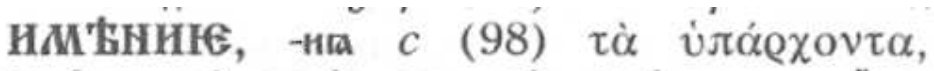
v๊ $\pi \alpha \varrho \xi \iota \varsigma, \tau \grave{\alpha} \quad \chi \varrho \eta ́ \mu \alpha \tau \alpha, \tau \grave{\alpha} \quad \pi \varrho \alpha ́ \gamma \mu \alpha \tau \alpha$, ő $\sigma \alpha$



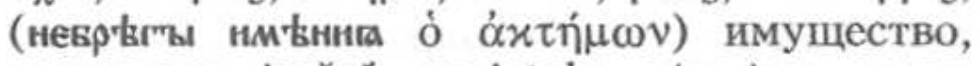




una uмkнье $I$ 15, 12 Зогр Мар Ас Сав; врана Аревле тво вом - нжже цмаші в'ъ цм'внін Клоц 4 a 31 (сьревромювьствига съказаниє Супр 411, 6-7); нмтнига ми въсхоть' мевр'вгын нмыннга Супр 432, 23 и 24 им вни ка сожено см. заложити.-- Зогр Мар Ас Сав Ен Син Eвx Cуnр Рыл.-Сp. нманик, нмьнинце, съкровнце 
Завершает основную словарную статью вторая справочная часть. Она включает перечень всех рукописей, в которых употреблено заглавное слово.

Как видим, словарная статья строится так же, как в двуязычных словарях древних языков, например в «Латинско-русском словаре И. Х. Дворецкого, «Греческо-русском словаре» А. Д. Вейсмана и «Полном церковнославянском словаре» [7-9]. Словарные статьи «Старославянского словаря» и таких исторических словарей, как «Материалов для словаря древнерусского языка» И. И. Срезневского, «Словаря русского языка XI-XVII вв.» и «Словаря древнерусского языка (XI-XIV вв.)» [10-12] во многом схожи.

Однако приведенный пример словарной статьи слова ИМЂНИЕ показывает не только традиционность, но и своеобразие в построении словарной статьи «Старославянского словаря». Во-первых, это не двуязычный (как обычно бывает), а трехъязычный словарь, поскольку дается перевод не только на русский, но и на чешский язык. По мнению Р. М. Цейтлин, эти «переводы представляют и узкоспециальный интерес. В словарной статье сконцентрирован лексический материал, который во многих случаях может служить отправной точкой для дальнейших сравнительно-исторических сопоставлений славянских языков различных групп. Чешские переводы для русского читателя, как и русские переводы для чешского читателя, помимо основной цели объяснения старославянского слова - в отдельных случаях помогут ознакомиться с историей данного слова и в другом родственном языке» [5, с. 50]. Например, старославянское ВОНЯТИ - русское «пахнуть» - чешское «vonět» [5, с. 121], старославянское ЧРЬВЛЕНЬ - русское «красный» - чешское «červený» [5, c. 782].
На наш взгляд, наиболее оригинальная часть словарной статьи находится в самом ее конце, после перечня рукописей за пометой Ср. («сравни»). Здесь приводятся, как отмечает Р. М. Цейтлин, «ссылки на собственно лексические дублеты и синонимы данного слова» [5, с. 54]. Они связываются между собой перекрестными ссылками и приводятся в алфавитном порядке. Например, слово МЫСЛЬ имеет ссылки на слова: ПОМЫСЛЬ, ПОМЫШЛЕНИЕ, РАЗОУМЬ, СЪМЫСЛЬ, ОУМЬ, ОУМЫШЛЕНИЕ [5, с. 337], слово СКРЬБЬНЪ - на слова ПЕЧАЛЬНЪ, ПРИСКРЬБЬНЪ, ОУНЫЛЬ [5, с. 608], слово РЕЩИ - на слова ВЪЗГЛАГОЛАТИ, ВЂЩАТИ, ГЛАГОЛАТИ, ИЗДРЂЩИ, НАРИЦАТИ, ПОВЂДЂТИ, ПРОРЕЩИ, ПРОРИЦАТИ, СИРЂЧЬ, СЪКАЗАТИ [5, с. 581]. Чаще это слова одной части речи, но иногда - разных. Например, частица СИРЂЧЬ приводится при глаголе РЕЩИ. Большинство слов в «Старославянском словаре» имеют при себе помету $C p$.

Анализ словарных статей, содержащих такую часть, поставил перед нами вопрос: всегда ли приводимые после пометы $C p$. слова являются собственно лексическими дублетами или синонимами? Мы сделали попытку ответить на этот вопрос, рассмотрев слова, называющие жилище. Эти слова занимают важное место в картине мира человека того времени. Т. И. Вендина в книге «Средневековый человек в зеркале старославянского языка» пишет: «Что касается локативов, относящихся собственно к человеку, то среди них выделяется довольно значительная группа слов, связанных с обозначением его жилища...» [13, с. 177].

Мы сделали выборку из «Старославянского словаря» слов-названий жилища (табл. 1). Заглавные слова мы поместили в первый столбец по алфавиту, а в скобках указали количество употреблений слова в рукописях и далее 
Вестник Новосибирского государственного педагогического университета

2(24)2015 www.vestnik.nspu.ru ISSN 2226-3365

- значение. Если значений несколько, они отделены точкой с запятой. Выборку мы начали с лексем ДОМъ и ЖИЛИЩЕ, а далее двигались по словарным статьям всех слов после пометы $C p$. Во второй столбец мы поместили дублеты и синонимы, которые каждое слово имеет в конце словарной статьи.

Таблица 1.

Слова, называющчие жилище, в "Старославянском словаре (по рукописям X-XI веков)»

\begin{tabular}{|c|c|}
\hline Заглавное слово & Слова после пометы $C p$. \\
\hline ВЪСЕЛЕНИЕ (4) «обиталище, жилище» & ВЪСЕЛЕНАЯ, ЖИЛИЩЕ, СЕЛИЩЕ \\
\hline $\begin{array}{l}\text { ДВОРЬ (60) } \\
\text { «Двор» }\end{array}$ & ДОМЪ, ЖИЛИЩЕ, ОГРАДА \\
\hline $\begin{array}{l}\text { ДОМъ (> 100) } \\
\text { «дом, жилище» }\end{array}$ & ДВОРЬ, ХЛЪВИНА, ХРАМИНА, ХРАМЪ \\
\hline ЖИЛИЩЕ (33) «жилище» & ДВОРЬ, ДОМЬ, ЖИЩЕ, ОБИТЬЛЬ, СКИНИЯ \\
\hline $\begin{array}{l}\text { ЖИЩЕ (2) } \\
\text { «жилище, обиталище» }\end{array}$ & ЖИЛИЩЕ \\
\hline $\begin{array}{l}\text { ЗЬДАНИЕ (15) «постройка, здание»; «со- } \\
\text { творение, создание» }\end{array}$ & ЗЬДЪ, СЪЗЬДАНИЕ, СЪТВОРЕНИЕ \\
\hline $\begin{array}{l}\text { ЗЬДД (1) } \\
\text { «стена, постройка» }\end{array}$ & ЗЬДАНИЕ \\
\hline $\begin{array}{l}\text { КЛЂТЬ (16) } \\
\text { «каморка, хижина» }\end{array}$ & КЛЂТЪКА, ХЛЪВИНА, ХЫЗИНА \\
\hline кЛЪТЬКА (5) «каморка, хижина» & КЛЂТЬ, ХЛЂВИНА, ХЫЗИНА \\
\hline $\begin{array}{l}\text { КРОВЫ (45) } \\
\text { «крыша»; «шатер, жилище»; «скрытое ме- } \\
\text { сто, тайник»; «охрана, защита, покрови- } \\
\text { тельство» }\end{array}$ & $\begin{array}{l}\text { ПОКРОВЪ, СКИНИИ, СТЕЛЯ, СТРОПЬ, СТРЪХА, } \\
\text { СЬКРОВЬ, ТАИЛИЩЕ }\end{array}$ \\
\hline $\begin{array}{l}\text { КљЩА (1) } \\
\text { «шалаш, хижина, палатка» }\end{array}$ & СКИНИИ, ХЛЪВИНА, ХЫЗИНА, ХЫЗЪ \\
\hline $\begin{array}{l}\text { ОБИТЂЛЬ (21) «жилище, жилье»; } \\
\text { «келья, скит» }\end{array}$ & ЖИЛИЩЕ \\
\hline $\begin{array}{l}\text { ОЧРЫЩЕ (1) } \\
\text { «шатер, жилище» }\end{array}$ & КРОВЬ, СКИНИИ \\
\hline $\begin{array}{l}\text { СЕЛИЩЕ (1) } \\
\text { «место поселения, пребывания» }\end{array}$ & ЖИЛИЩЕ, СЕЛО \\
\hline $\begin{array}{l}\text { СЕЛО (> 100) } \\
\text { «двор, имение, усадьба»; «жилище»; } \\
\text { «пастбище» }\end{array}$ & ВЬСЬ, ГРАДЬЦЬ, НИВА, СТРАНА \\
\hline $\begin{array}{l}\text { СКИНИИ (9) } \\
\text { «шатер, жилище»; спец. «святилище» }\end{array}$ & КЖЩА, СЂНЬ, ХЛЪВИНА, ХЫЗИНА, ХЫЗЪ \\
\hline $\begin{array}{l}\text { СҺHb (2) } \\
\text { «шатер» }\end{array}$ & КРОВЬ, СКИНИИ \\
\hline $\begin{array}{l}\text { ХЛЋВИНА (14) } \\
\text { «дом, здание, постройка; жилье»; } \\
\text { «пристанище, приют» }\end{array}$ & $\begin{array}{l}\text { ДОМЪ, КЛЂТЬ, КЛЂТЬКА, КЖЩА, СКИНИИ, } \\
\text { ХРАМИНА, ХРАМЬ, ХЫЗИНА, ХЫЗЬ }\end{array}$ \\
\hline
\end{tabular}


Вестник Новосибирского государственного педагогического университета

2(24)2015 www.vestnik.nspu.ru ISSN 2226-3365

\begin{tabular}{|c|c|}
\hline $\begin{array}{l}\text { ХРАМИНА (55) } \\
\text { «дом, здание» }\end{array}$ & ДОМЬ, ЗЬДАНИЕ, ХРАМЬ \\
\hline $\begin{array}{l}\text { ХРАМЬ (60) } \\
\text { «дом, здание»; «жилье»; } \\
\text { спещ. «храм, святилище, церковь» }\end{array}$ & $\begin{array}{l}\text { ДОМЬ, ЗЬДАНИЕ, КЛЬТЬ, КЛЬТЬКА, КЖЩА, } \\
\text { СКИНИИ, ХЛЬВИНА, ХРАМИНА, ХЫЗИНА, } \\
\text { ХЫЗЬ, ЦРЬКЫ }\end{array}$ \\
\hline $\begin{array}{l}\text { ХЫЗИНА (15) } \\
\text { «хижина, келья, каморка» }\end{array}$ & $\begin{array}{l}\text { КЛЂТЬ, КЛЂТЬКА, КЖЩА, СКИНИИ, ХЛЪВИНА, } \\
\text { ХЫЗЬ }\end{array}$ \\
\hline $\begin{array}{l}\text { ХЫЗЪ (1) } \\
\text { «домик, хижина» }\end{array}$ & $\begin{array}{l}\text { КЛЬТЬ, КЛЬТЬКА, КЖЩА, СКИНИИ, ХЛЬВИНА, } \\
\text { ХЫЗИНА }\end{array}$ \\
\hline
\end{tabular}

Анализ материала таблицы позволяет сделать следующие выводы. Во-первых, среди названий жилища есть гапаксы, т. е. слова, которые встречаются в старославянских текстах только один раз: ЗЬДЪ, КЖЩА, ОЧРЬЩЕ, СЕЛИЩЕ и ХЫЗЪ. Из этих пяти слов три связаны с однокоренными производными или производящими словами: ЗЬДАНИЕ - ЗБДъ, СЕЛИЩЕ - СЕЛО, ХЫЗЬ - ХЫЗИНА. Два раза встречается слово ЖИЩЕ, связанное с ЖИЛИЩЕ. Нам думается, их действительно можно считать дублетами соответствующих слов с высокой частотностью.

Во-вторых, слова ДВОРЪ, КРОВЪ, СЕЛО не могут, по-видимому, в полной мере считаться дублетами или синонимами наименований жилища, что видно и по их значениям, и по словам, которые даны к ним с пометой $C p$.

Сопоставление значений всех наименований жилища из сделанной выборки и данных к ним так называемых дублетов и синонимов позволяет сделать вывод о том, что слова, называющие жилище, представляют собой не ряд дублетов или синонимов, а скорее тематическую группу слов, т. е. ряд слов, более или менее близко совпадающих по своему основному (стержневому) семантическому содержанию [14, с. 118]. О таких группах в 1957 г. писал Ф. П. Филин в своей работе «О лексикосемантических группах слов»: «Такого рода объединения слов, основывающихся не на лексико-сематических связях, а на классификации самих предметов и явлений, можно назвать тематическими словарными группами» (цит. по: [15, с. 186]).

В этой тематической группе представлены общие и частные названия. Слова жИЛИЩЕ и ДОМъ обладают наиболее общим значением, в отличие от лексем, обозначающих разные виды жилища:

a) небольшого размера (КЛЂТь и КЛЂТЬКА, ср.: каморка - небольшая комната, хижина - небольшой сельский домик, избушка),

б) временного, сделанного из веток или соломы, например: КљЩА (шалаш - палатка из веток, соломы, палатка - временное помещение из натянутой на остов ткани, шкуры), ОЧРЬЩЕ и СЪНЬ (шатер - большая палатка, крытая обычно тканью). Ряд слов, наряду с общим значением «жилище», развивают переносные значения а) «места обитания», б) «места, где можно найти пристанище или приют». Например: а) ОБИтЂЛЬ («келья, скит»), СКИНИИ («святилище»), ХРАМЬ («церковь»); б) ХЛЪВИНА, КРОВЬ.

В заключение можно утверждать, что в словарной статье дается информация большего объема, чем заявили авторы «Старославянского словаря». Мы можем не только узнать значение слова, его употребление в канонических текстах, но и понять, в какие 
группы оно входит (тематические или лексико-семантические), определить его место в лексической системе старославянского языка. Таким образом, «Старославянский словарь» занимает в типологии словарей особое место: он является одновременно трехъязычным и историческим словарем. Структура словарной статьи позволяет считать «Старославянский словарь (по рукописям X-XI веков)» не просто словарем для чтения и перевода, но книгой, благодаря которой можно узнать и понять средневековую христианскую письменность и культуру.

\section{СПИСОК ЛИТЕРАТУРЫ}

1. Русская лексикография: пособие для вузов. - М.: Дрофа, 2004. - 288 с.

2. Лукьянова Н. А. Современный русский язык: Лексикология. Фразеология. Лексикография: учебнометодическ. пособие. - Новосибирск: Редакционно-издательский центр НГУ, 2003. - 144 с.

3. Лингвистический энциклопедический словарь / гл. ред. В. Н. Ярцева. - М.: Советская энциклопедия, 1990. - 685 с.

4. Крысин Л. П. Современный русский язык: Лексическая семантика. Лексикология. Фразеология. Лексикография: учеб. пособие. - М.: Академия, 2007. - 240 с.

5. Старославянский словарь (по рукописям Х-ХІ веков) / под ред. Р. М. Цейтлин, Р. Вечерки и Э. Благовой. - М.: Русский язык, 1994. - 842 с.

6. Крысин Л. П. Слово в современных текстах и словарях: очерки о русской лексике и лексикографии. - М.: Знак, 2008. - 320 с.

7. Вейсман А. Д. Греческо-русский словарь. - Репр. 5-го изд. 1899 г. - М.: Греко-латинский кабинет Ю. А. Шичалина, 1991. - 1370 с.

8. Дворецкий И. Х. Латинско-русский словарь. - 7-е изд. - М.: Русский язык, 2002. - 846 с.

9. Полный церковнославянский словарь / сост. Г. Дьяченко. - М.: Изд. отдел Моск. Патриархата, 1993. -1120 c.

10. Срезневский И. И. Материалы для словаря древнерусского языка: в 3 тт. - М.: Знак, 2003. - Т. 1. A - K. $-776 \mathrm{c}$.

11. Словарь древнерусского языка (XI-XIV вв.): в 10 тт. / гл. ред. Р. И. Аванесов. - М.: Русский язык, 1988. - Т. 1: (а - възаконятися).- 526 с.

12. Словарь русского языка XI-XVII вв. - М.: Наука, 1975. - Вып. 1. (А-Б). - 371 с.

13. Вендина Т. И. Средневековый человек в зеркале старославянского языка.- М.: Индрик, 2002. $336 \mathrm{c}$.

14. Ахманова О. С. Словарь лингвистических терминов. - 2-е изд.- М.: Советская энциклопедия, 1969. $-607 \mathrm{c}$.

15. Шмелев Д. Н. Современный русский язык: Лексика: учеб. пособие. - М.: Просвещение, 1977. - 335 с. 
Targonskaya Elena Petrovna, Doctor of Philological Science, Associated Professor, Language Theory and Cross-Cultural Communication Department, Novosibirsk State Pedagogical University, Novosibirsk, Russian Federation.

E-mail: targilena@yandex.ru

\title{
WORDS MEANING, DWELLING PLACE, IN THE OLD SLAVONIC DICTIONARY (BASED ON THE MANUSCRIPTS OF THE $10^{\text {TH }}-11^{\text {TH }}$ CENTURIES): STRUCTURE OF A DICTIONARY ENTRY
}

\begin{abstract}
The article analyzes the words meaning dwelling place mentioned in the Old Slavonic Dictionary (based on the manuscripts of the $10^{\text {th }}-11^{\text {th }}$ centuries). The aim of the article is to reveal the specific structure of the dictionary entry in the given dictionary. It is noted that in the Old Slavonic Dictionary, which on the one hand can be attributed to bilingual dictionaries and on the other hand to historical dictionaries, the dictionary entry is composed in a particular way. Apart from the traditional components, it is worth noting that a translation into two languages (Russian and Czech) is given. Furthermore, at the end of the dictionary entry after the note compare, as the authors of the dictionary mark, synonyms and doublets are presented. The consideration of the words meaning dwelling place makes it possible to cast doubts on the status of these correlations. A continuous sampling of the words meaning $d$ welling place and their so-called synonyms and doublets was made from the Old Slavonic Dictionary. The analysis of the material obtained allows us to state that these words represent a thematic group of words-names of dwelling place and the Old Slavonic Dictionary itself (based on the manuscripts of the $10^{\text {th }}-11^{\text {th }}$ centuries) is a book that provides the comprehension of the medieval Christian written language and culture rather than simply a dictionary for reading and translating.
\end{abstract}

Keywords

Old Slavonic Language, dictionary entry, synonyms, thematic group

\section{REFERENCES}

1. Russian Lexicography. Handbook for Higher Education Organizations. Moscow, Drofa Publ., 2004, 288 p. (In Russian)

2. Lukyanova N. A. Modern Russian Language: Lexicology. Phraseology. Lexicography. Manual for students and post-graduates of philological and other specialties of universities. Novosibirsk, Novosibirsk State University Publ., 2003. 144 p. (In Russian)

3. Linguistic Encyclopaedic Dictionary. Ed. V. N. Yartseva. Moscow, Sovetskaya Encyclopaedia Publ., 1990, 685 p. (In Russian)

4. Krysin L. P. Modern Russian Language. Lexical semantics. Lexicology. Phraseology. Lexicography. Manual for students of philological faculties of higher education organizations. Moscow, Akademiya Publ., 2007, 240 p. (In Russian)

5. Old Slavonic Dictionary (on manuscripts of the 10th-11th centuries). Eds. R. M. Tseitlin, R. Vecherka, E. Blagova. Moscow, Russkij Yazyk Publ., 1994, 842 p. (In Russian) 
6. Krysin L. P. A Word in Current Texts and Dictionaries: Essays on Russian Vocabulary and Lexicography. Moscow, Znak Publ., 2008, 320 p. (In Russian)

7. Veisman A. D. Greek-Russian dictionary. Reprint of the 5th edition, 1899. Moscow, Yu. A. Shichalin's Greek-Latin Cabinet Publ., 1991, 1370 p. (In Russian)

8. Dvoretskii I. Kh. Latin-Russian Dictionary. 7th edition. Moscow, Russkij Yazyk Publ., 2002, 846 p. (In Russian)

9. Full Church Slavonic Dictionary. Comp. G. Dyachenko. Moscow, Moscow Patriarchy Publ., 1993, 1120 p. (In Russian)

10. Sreznevskii I. I. Materials for the Dictionary of the Old Russian Language. In 3 vol. Moscow, Znak Publ., 2003, vol. 1. A-K, 776 p. (In Russian)

11. Dictionary of the Old Russian Language (11th-14th cent.). 10 vol. Ed. R. I. Avanesov. Moscow, Russkij Yazyk Publ., 1988, vol. 1. (а - възаконятися), 526 р. (In Russian)

12. Dictionary of the Russian Language of the 11th-17th cent. Moscow, Nauka Publ., 1975, Issue 1. (A-Б), 371 p. (In Russian)

13. Vendina T. I. A Medieval Man in the Mirror of the Old Slavonic Language. Moscow, Indrik Publ., 2002, 336 p. (In Russian)

14. Akhmanova O. S. Dictionary of Linguistic Terms. 2nd edition. Moscow, Sovetskaya Encyclopaedia Publ., 1969, 607 p. (In Russian)

15. Shmelev D. N. Modern Russian Language. Lexicology. Manual for students. Moscow, Prosveshchenie Publ., 1977, 335 p. (In Russian) 